\title{
Relationships between Functional Status, Activities of Daily Living and Depression by Time since Stroke Onset in Elderly Patients with Acute Stroke
}

\author{
Gyeong-A Park ${ }^{1}$, Keun-Bae $\mathrm{Oh}^{2}$, Jin-A Hwang ${ }^{3}$, Kyung-Yoon $\mathrm{Kim}^{3}$ and Ji-Young \\ Baik $^{1}$ \\ ${ }^{1}$ Department of Occupational Therapy Dongshin University, Naju, Korea, \\ ${ }^{2}$ Department of Occupational Therapy Bucheon Seongshin Hospital, Bucheon, \\ Korea, \\ ${ }^{3}$ Department of Physical Therapy Dongshin University, Naju, Korea, \\ ${ }^{1}$ Winter121@daum.net, ${ }^{2}$ heb1221@naver.com, ${ }^{3}$ hwangxena@naver.com, \\ redbead7@daum.net, ${ }^{3}$ jybaek@dsu.ac.kr
}

\begin{abstract}
The objective of the present study was to examine changes in functional status, performance of activities of daily living (ADLs), and depression between initial onset of stroke and 1 and 3months post-stroke; furthermore, we sought to determine the changes in the correlations between these factors over time. The study subjects were 42 patients, aged 65 years or older, undergoing rehabilitation treatments after being diagnosed with stroke. Evaluations of functional status, performance of ADLs, and depression were performed using Korean versions of the National Institutes of Health Stroke Scale, Modified Barthel Index, and Geriatric Depression Scale Short Form, respectively. The results showed that changes in functional status, performance of ADLs, and depression between onset of stroke and 1 and 3months post-stroke were statistically significant. Within 1 week from the onset of stroke, there was a significant correlation between the total scores of functional status and performance of ADLs and depression. At 1month post-stroke, there was a significant correlation between the total scores for functional status and performance of ADLs; however, functional status and depression were no longer significantly related, although performance of ADLs was significantly correlated with depression. Finally, at 3monthspoststroke, significant correlations were found between functional status and performance of $A D L s$, and between depression and performance of ADLs. Thus, functional status, performance of $A D L s$, and depression in elderly stroke patients showed significant changes by time since stroke onset. Although functional status and performance of ADLs were consistently correlated over time, depression showed weaker correlations with functional status over time, but showed consistent correlations with performance of ADLs.
\end{abstract}

Keywords: Post-stroke depression, Functional recovery of rehabilitation, $A D L$

\section{Introduction}

Stroke is a medical condition that causes sudden neurological symptoms, such as impaired motor function, sensory deficit, impaired cognition and speech, and loss of consciousness. It results in a serious degradation of bodily functions compared to other elderly in the same age group and increases elderly people's dependency on family or caregivers for performing activities of daily living (ADLs) [1]. Geriatric diseases are often recognized simply as physiological conditions caused by aging. However, elderly people often experience depressive states due to physical aging and various socio-psychological factors, such as economic deprivation, emotional instability, and social isolation, which serve as causes of decreased confidence in actively responding to changes in physical function and reduce independent performance of ADLs [2]. In a study by Han [3] on the differences in ADL performance, family support, and depression in patients with post-stroke 
hemiplegia, it was found that the severity of their ADL deficits had a significant influence on depression, because patients experience a range of different problems depending on what ADLs are impaired. Park [4] reported that lower ADL performance capabilities were associated with higher levels of anxiety and depression.

In terms of functional recovery in stroke patients, factors known to affect prognosis include age, degree of motor disability, severity of brain injury, time of starting rehabilitation, existence of systemic disease, degree of cognitive and perceptive deficiencies, and psychoenvironmental factors - in particular, depressive symptoms, which vary in severity according to time since onset of stroke and patients' cognitive states [5]. Therefore, it is important to clearly understand the initial functional state and how functional states changeover time.

Accordingly, the present study examines the changes in functional status, performance of ADLs, and depression by time since stroke onset in elderly patients with acute stroke, and determines the correlations between these variables at the initial, acute, and subacute phases. The findings will aid in predicting recovery in elderly patients with stroke, setting goals, and planning systematic therapeutic approaches for comprehensive rehabilitation.

\section{Subjects and Methods}

\subsection{Study Participants}

The present study included 42 inpatients and outpatients aged 65 years or older who were receiving rehabilitation after being diagnosed with stroke from $C$ National University Hospital in G City in South Korea. The selection criteria were as follows. Patients had to (1) be diagnosed with stroke and have a score of $\geq 24$ on the Korean version of the MiniMental State Examination (MMSE-K); (2) have a clear state of consciousness and be capable of communicating, being interviewed, and cooperating; (3) have an occurrence of stroke of less than 6 months; and (4) understand the purpose and scope of this study and consent to participate.

\subsection{MMSE-K(Korean version of the Mini-Mental State Examination)}

The MMSE-K, adapted by Young-Chul Kwon and Young-Han Park [6], was used. The MMSE-K is a simple cognitive function screening tool that is widely used due to its high reliability and validity.

\subsection{K-NIHSS(Korean version of the National Institutes of Health Stroke Scale)}

Functional status was measured using the Korean version of the National Institutes of Health Stroke Scale (K-NIHSS) from the United States. The K-NIHSS is an evaluation tool designed to assess the initial disabilities in stroke patients and for follow-up monitoring of neurological functional state. Higher scores indicated greater severity of disability. A high test-retest reliability (rho>.721; $p<.01$ ) was observed [7].

\subsection{K-MBI(Korean version of the Modified Barthel Index)}

Performance of ADLs was measured using the Korean version of the Modified Barthel Index (K-MBI). The level of concordance between raters at the time of development was very high, with a Kendall coefficient of .95-.98 [8].

\subsection{GDS-K(Korean version of the Geriatric Depression Scale Short Form)}

Depression was measured using the Korean version of the Geriatric Depression Scale Short Form (GDS-K) by Baek-Seok Ki [9]. In the study by Baek-Seok Ki [9], the internal 
consistency (Cronbach's $\alpha$ ) of the tool was .88 , indicating a greater than moderate level of reliability.

\subsection{Data Analysis}

In the present study, a frequency analysis, using SPSS Win 19.0, was performed to calculate the frequencies and percentages for the general characteristics of the elderly patients with stroke. Functional status, ADLs, and depression at the onset of stroke and at 1 and 3monthspost-strokewere described using descriptive statistics. To examine the differences in functional status, performance of ADLs, and depression by time since onset of stroke, we performed a repeated-measures ANOVA. To assess the relations between functional status, performance of ADLs, and depression in elderly stroke patients at the onset of stroke and at 1 and 3months post-stroke, Pearson's correlation coefficient was used.

\section{Results}

\subsection{General Characteristics}

The general characteristics of the study participants are as follows (Table 1).

Table 1. Clinical Characteristics of the Subjects

\begin{tabular}{cccc}
\hline Variables & Categories & $\mathrm{n}$ & $\%$ \\
\hline Gender & Male / Female & $26 / 16$ & $61.9 / 38.1$ \\
Age(years) & $65-74 / 75 \leq$ & $28 / 14$ & $66.7 / 33.3$ \\
Diagnosis & Infarction / hemorrhage & $23 / 19$ & $54.8 / 45.2$ \\
Paretic Side & Rt. / Lt. / Both & $14 / 25 / 3$ & $33.3 / 59.5 / 7.1$ \\
& Uneducated / Elementary & $5 / 10$ & $11.9 / 23.8$ \\
Education & Middle school / High school $\uparrow$ & $15 / 12$ & $35.7 / 28.6$ \\
& Diabetes / Hypertension & $7 / 21$ & $16.7 / 50.0$ \\
Comorbidity & Hyperlipidemia / Heart disease / & $2 / 3 / 9$ & $4.8 / 7.1 / 21.4$ \\
& No & $26 / 7$ & $61.9 / 16.7$ \\
Caregiver & Spouse / Children & $1 / 6 / 2$ & $2.4 / 14.3 / 4.8$ \\
& Family / Caretaker / No & $15 / 27$ & $35.7 / 64.3$ \\
Smoking & Yes / No & $27 / 15$ & $64.3 / 35.7$ \\
Alcohol & Yes / No & &
\end{tabular}

Value are given as mean \pm standard deviation

\subsection{Changes in Functional Status, Performance of ADLs, and Depression by Time Since Stroke Onset}

Mean functional status scores at within 1 week, 1 month, and 3 months post-stroke were $7.98 \pm 4.77,5.21 \pm 3.55$, and $2.83 \pm 2.78$, respectively; the mean scores for performance of ADLs were $39.52 \pm 25.81,61.83 \pm 25.11$, and $77.52 \pm 21.71$, respectively; and the mean scores for depression were $8.74 \pm 3.09,6.57 \pm 3.33$, and $4.83 \pm 2.76$, respectively. Thus, all variables showed improvement over time. The results of repeated-measures ANOVAs for each variable showed statistically significant differences between time points $(p=.001)($ Table 2). 
Table 2. K-NIHSS, K-MBI, GDS-K by Time Since Stroke Onset

\begin{tabular}{ccccc}
\hline & 1 weeks & 1 months & 3 months & $p$ \\
\hline K-NIHSS & $7.98 \pm 4.77$ & $5.21 \pm 3.55$ & $2.83 \pm 2.78$ & .001 \\
K-MBI & $39.52 \pm 25.81$ & $61.83 \pm 25.11$ & $77.52 \pm 21.71$ & .001 \\
GDS-K & $8.74 \pm 3.09$ & $6.57 \pm 3.33$ & $4.83 \pm 2.76$ & .001 \\
\hline
\end{tabular}

Value are given as mean \pm standard deviation

\subsection{Correlations between Functional Status, Performance of ADLs, and Depression within 1 week Post-stroke}

The correlations between functional status (K-NIHSS), performance of ADLs (K-MBI), and depression within 1 week post-stroke are shown below (Table 3).

Table 3. Correlations between K-NIHSS, K-MBI, and GDS-K within 1 Week Post-stroke

\begin{tabular}{|c|c|c|c|c|c|c|c|c|c|c|c|c|}
\hline & $\begin{array}{c}\text { Level of } \\
\text { consciousnes }\end{array}$ & ${ }_{\text {sgaze }}^{\text {Best }}$ Visual & ${ }_{11}^{\text {Faciall }}$ & $\begin{array}{l}\text { IMotorl } \\
\text { arm }\end{array}$ & $\begin{array}{l}\text { Motor } \\
\text { leg }\end{array}$ & $\begin{array}{l}\text { Limb } \\
\text { ataxia }\end{array}$ & & $\begin{array}{c}\text { Best } \\
\text { anguage }\end{array}$ & Dysarthr & $\begin{array}{l}\text { Exinction } \\
\text { and attention }\end{array}$ & $\begin{array}{c}\text { K- } \\
\text { NIHSS } \\
\text { Total } \\
\text { score }\end{array}$ & ${ }_{\mathrm{G}}^{\mathrm{S}} \mathrm{SS}$ \\
\hline $\begin{array}{l}\text { Personal } \\
\text { hygiene }\end{array}$ & $-.323^{*}$ & $.583^{* *-}-.568^{* *}$ & $-.381^{*}$ & $-.590^{* *}$ & $-.666^{* *}$ & -.170 & $-.642^{* *}$ & -.116 & -.249 & $-.618^{* *}$ & $-.784^{* *}$ & $.451^{* *}$ \\
\hline $\begin{array}{c}\text { Bathing } \\
\text { self }\end{array}$ & -273 & $.399^{* *-.478^{* *}}$ & -.249 & $-.412^{* *}$ & $-.537^{* *}$ & -.153 & $-.416^{* *}$ & -.058 & -.046 & $-.548^{* *}$ & $-.579^{* *}$ & $.444^{* *}$ \\
\hline Feeding & $-.463^{* *}$ & $.381^{*}-.357^{*}$ & $-.394^{* *}$ & $-.474^{* *}$ & $-.535^{* *}$ & -.179 & $-.558^{* *}$ & -.085 & $-.304^{* *}$ & $-.441^{* *}$ & $-.669^{* *}$ & -299 \\
\hline Toilet & $-.327^{*}$ & $.463^{-* *}-.340^{*}$ & $-.334^{*}$ & $-.645^{* *}$ & $-.687^{* *}$ & -.095 & $-.646^{* *}$ & -.039 & -.204 & $-.500^{* *}$ & $-.739^{* *}$ & . $540^{* * *}$ \\
\hline $\begin{array}{c}\text { Stair } \\
\text { climbing }\end{array}$ & -.220 & $.342^{*}-.378^{*}$ & $-.330^{*}$ & $-.537^{* *}$ & $-.557^{* *}$ & -.087 & $-.545^{* *}$ & .101 & -.117 & $-.421^{* *}$ & $-.596^{* *}$ & $.525^{* *}$ \\
\hline Dressing & $-.415^{* *}$ & $.442^{* *}-.302$ & $-.419^{* *}$ & $-.662^{* * *}$ & $-.638^{* *}$ & -.138 & $-.657^{* *}$ & -.066 & -.304 & -.383 & $-.751^{* *}$ & $.566^{* *}$ \\
\hline $\begin{array}{l}\text { Bowel } \\
\text { control }\end{array}$ & $-.358^{*}$ & $.468^{* *}-.008$ & -.243 & $-.399^{* *}$ & $-.468^{* *}$ & -.296 & $-.431^{* *}$ & -.140 & -.233 & $-.570^{*}$ & $-.578^{* *}$ & -.195 \\
\hline $\begin{array}{l}\text { Bladder } \\
\text { control }\end{array}$ & $-.379^{*}$ & $.504^{-}-327^{*}$ & -.198 & $-.395^{* *}$ & $-.492^{* *}$ & $-.310^{*}$ & $-.538^{* *}$ & -.087 & $-.311^{*}$ & $-.521^{* *}$ & $-.635^{* *}$ & -.222 \\
\hline $\begin{array}{l}\text { Ambulation/ } \\
\text { Wheelchair }\end{array}$ & -.269 & $.430^{* *}-.440^{* *}$ & $-.369^{*}$ & $-.595^{* *}$ & $-683^{* *}$ & -.127 & $-.595^{* *}$ & .028 & -.122 & $-.428^{* *}$ & $-.696^{* *}$ & $.471^{* *}$ \\
\hline $\begin{array}{l}\text { chair/ } \\
\text { bed transfer }\end{array}$ & $-.379^{*}$ & $.503^{* *-.480^{* *}}$ & $-.329^{*}$ & $-.613^{* *}$ & $-.704^{* *}$ & -.179 & $-.636^{* *}$ & -.039 & -.143 & $-.450^{* *}$ & $-.758^{* * *}$ & $.422^{-* *}$ \\
\hline $\begin{array}{l}\text { K-MBI } \\
\text { Total score }\end{array}$ & $-.393^{*}$ & $.516^{* *-}-.410^{* * *}$ & $-.361^{*}$ & $-.612^{* *}$ & $-.685^{* *}$ & -.205 & $-.657^{* *}$ & -.052 & -.236 & $-.547^{* *}$ & $-.777^{* *}$ & $-461^{* *}$ \\
\hline GDS & .257 & $\begin{array}{ll}.357^{*} \quad .159\end{array}$ & .259 & $.436^{* *}$ & $.378^{*}$ & -.115 & $.447^{* *}$ & .067 & .196 & $.357^{*}$ & $.474^{* *}$ & 1 \\
\hline
\end{tabular}

Korean Version of Modified Barthel Index, GDS-K: Geriatric Depression Scale Short Form; Korea Version

\subsection{Correlations between Functional Status, Performance of ADLs, and Depression within 1 Month Post-stroke}

The correlations between functional status (K-NIHSS), performance of ADLs (K$\mathrm{MBI}$ ), and depression at 1 month post-stroke are shown below (Table 4). 
Table 4. Correlations between K-NIHSS, K-MBI, and GDS-K within 1 Month Post-stroke

\begin{tabular}{|c|c|c|c|c|c|c|c|c|c|}
\hline & $\begin{array}{c}\text { Level of } \\
\text { consciousnes }\end{array}$ & $\begin{array}{l}\text { Best } \\
\text { s gaze }\end{array}$ & Visua & $\begin{array}{l}\text { FacialMotorMotor Limb } \\
\text { palsy arm leg ataxia }\end{array}$ & Sens & $\begin{array}{l}\text { Best } \\
\text { language }\end{array}$ & Dysarthria & $\begin{array}{l}\text { Exinction } \\
\text { a and } \\
\text { inattention }\end{array}$ & $\begin{array}{l}\text { K- } \\
\text { NIHSS } \\
\text { Total GDS } \\
\text { score }\end{array}$ \\
\hline $\begin{array}{l}\text { Personal } \\
\text { hygiene }\end{array}$ & -.100 & $317^{*}$ & * -.100 & $-.265-.500^{* *}-.531^{* *}-.074$ & $-.475^{* *}$ & -.049 & -.164 & -.002 & $-.606^{* *} .327^{*}$ \\
\hline Bathing self & -.100 &.$-9^{*}$ & $*-.170$ & $-.327^{*}-.500^{* *}-.550^{* *}-.077$ & $-.362^{*}$ & -.037 & .025 & .002 & $-.595^{* *} .453^{* *}$ \\
\hline Feeding & $-.324^{*}$ &.$-9^{*}$ & -.050 & $\begin{array}{llll}-.271 & -.199 & -.281 & -.326^{*}\end{array}$ & $-.386^{*}$ & -.190 & $-.376^{*}$ & .047 & $-.481^{* *}-.198$ \\
\hline Toilet & -.164 & -.297 & .049 & $-.413^{* *}-.675^{* *}-.688^{* *}-.104$ & $-.494^{* *}$ & -.013 & -.187 & -.122 & $-.762^{* *} .456^{* *}$ \\
\hline $\begin{array}{c}\text { Stair } \\
\text { climbing }\end{array}$ & .071 & -.199 & -.124 & $-.364^{*}-.618^{* *}-.660^{* *}-.148$ & $-.382^{*}$ & .250 & .207 & .036 & $-.616^{* *} .518^{* *}$ \\
\hline Dressing & -.202 & $.374^{*}$ & -.082 & $-.383^{*}-.671^{* *}-.655^{* *}-.038$ & $-.530^{* *}$ & -.036 & -.290 & -.285 & $-.767^{* *} .527^{* *}$ \\
\hline $\begin{array}{l}\text { Bowel } \\
\text { control }\end{array}$ & $-.420-^{* *}$ & $.357^{*}$ & .010 & $\begin{array}{lllll}-.210 & -.271 & -.237 & -.126\end{array}$ & -.163 & -.299 & -.303 & -.064 & $-.448^{* *}-.187$ \\
\hline $\begin{array}{l}\text { Bladder } \\
\text { control }\end{array}$ & -.293 & -.238 & .127 & $\begin{array}{llll}-.304 & -.264 & -.285 & -.144\end{array}$ & -.284 & -.190 & -.266 & -.040 & $-.448^{* *}-.205$ \\
\hline $\begin{array}{l}\text { Ambulation/ } \\
\text { Wheelchair }\end{array}$ & -.057 &.$-6^{*}$ & .030 & $-.394^{* *}-.642^{* * *}-732^{* *}-.230$ & $-.524^{* *}$ & .091 & -.100 & -.063 & $-.766^{* *} .402^{* *}$ \\
\hline $\begin{array}{c}\text { chair/ } \\
\text { bed transfer }\end{array}$ & -.116 & -.294 & -.220 & $-.401^{* *}-.718^{* *}-.725^{* *}-.105$ & $-.538^{* *}$ & .017 & -.148 & -.150 & $-.806^{* *} .415^{* *}$ \\
\hline $\begin{array}{l}\text { K-MBI } \\
\text { Total score }\end{array}$ & -.192 & $.380^{-}$ & .089 & $-.432^{* *}-.663^{* *}-.704^{* *}-.188$ & $-.538^{* *}$ & -.032 & -.200 & -.086 & $-.815^{* *} 448^{* *}$ \\
\hline GDS & .165 & .084 & -.141 & $\begin{array}{llll}.202 & .275 & .278^{*} & -.090\end{array}$ & .204 & .036 & .085 & .019 & .261 \\
\hline
\end{tabular}

\subsection{Correlations between Functional Status, Performance of ADLs, and Depression within 3 month Post-stroke}

The correlations between functional status (K-NIHSS), performance of ADLs(K-MBI), and depression are shownbelow (Table 5).

\section{Table 5. Correlations between K-NIHSS, K-MBI, and GDS-K within 3 Months Post- stroke}

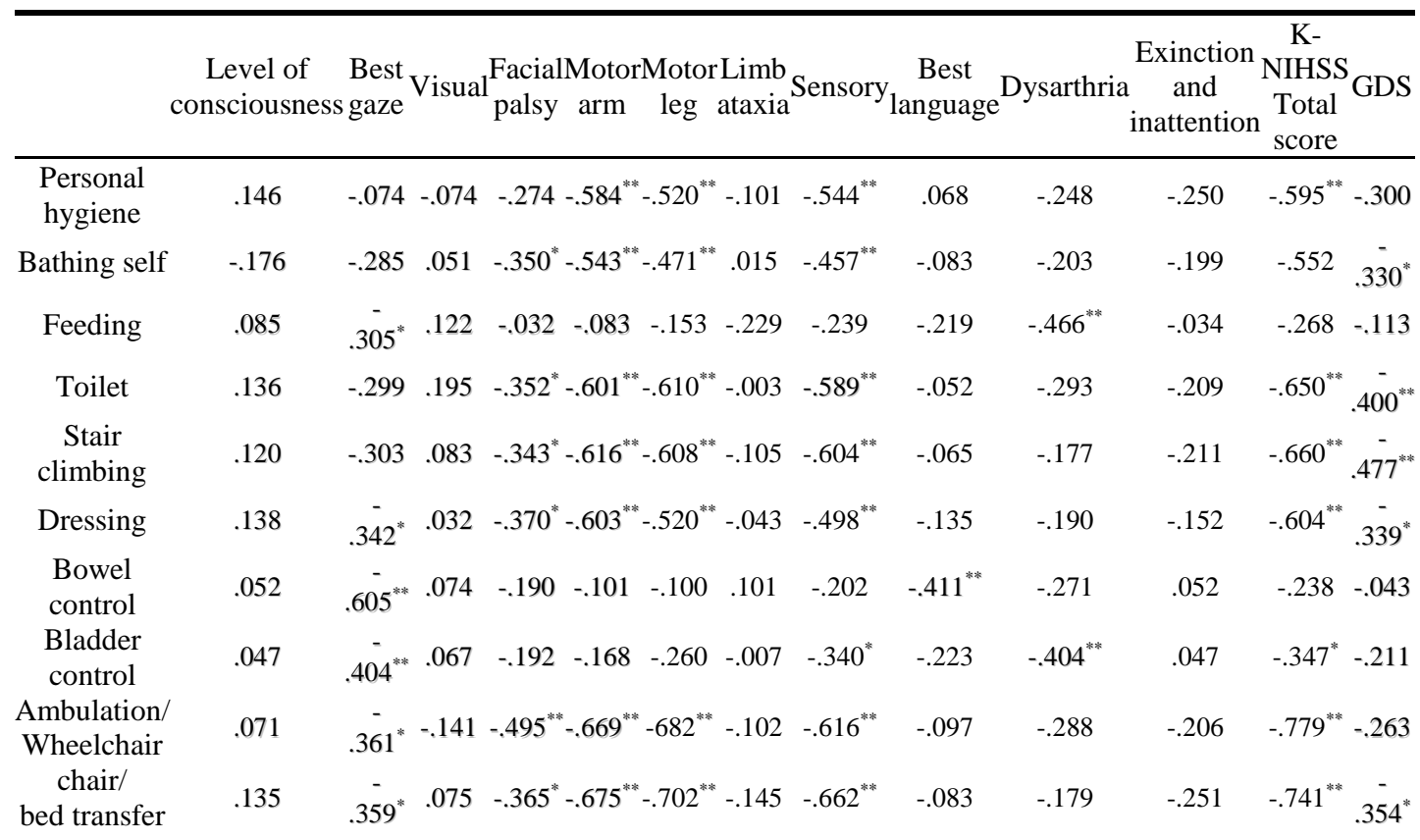




\begin{tabular}{llllllllllllll} 
K-MBI & & - & - & & & & & & & & \\
Total score & .127 & $.438^{* *}$ & .104 & $-.371^{*}-.605^{* *}-.610^{* *}$ & -.081 & $-.617^{* *}$ & -.177 & $-.340^{*}$ & -.179 & $-.705^{* *}-360^{*}$ \\
GDS & .181 & .014 & -.068 & .157 & $.310^{*}$ & $.339^{*}$ & -.130 & $.447^{* *}$ & .177 & .209 & -.162 & $.364^{*}$ & 1 \\
\hline
\end{tabular}

${ }^{*} p<.05,{ }^{* *} p<.01, \mathrm{~K}-\mathrm{NIHSS}$ : Korean Version of National Institutes of Health Stroke Scale, K-MBI: Korean Version of Modified Barthel Index, GDS-K: Geriatric Depression Scale Short Form; Korea Version

\section{Discussion}

In the present study, at time points of within 1 week, 1month,and 3monthspost-stroke, a pattern of improvement was seen in all three studied variables. Depressive symptoms initially exhibited a high score, but this score gradually decreased over time. Post-stroke depression is a common occurrence among stroke patients and it has been reported to occur in around one-third of patients during the acute and subacute phases of stroke [10]. In the present study, the participants were elderly stroke patients aged 65 years or older with an initial stage MMSE-K score of $\geq 24$ points (i.e., they showed normal cognitive functions). Furthermore, the participants showed improvements in functional status and performance of ADLs, which suggested that the improved performance of ADLs for up to3monthspost-strokeacted as a reducing factor for depression. To confirm this, multilateral investigations and studies on the factors that influence depression in elderly stroke patients are needed in the future.

Although significant correlations between most subcategories of functional status and performance of ADLs were observed within 1 week post-stroke in elderly stroke patients, depression was only significantly correlated with the best gaze, motor arm, motor leg, sensory, and extinction and in attention subcategories of functional status. At 1month post-stroke, there were no significant correlations between depression and the subcategories of functional status, and correlations were seen only in the subcategories of performance of ADLs. At 3months post-stroke, the subcategories of motor arm and motor leg were significantly correlated with subcategories of performance of ADLs, but showed weaker interrelationships with depression. After suffering a stroke, most patients complain of difficulties in performing ADLs and experience reduced self-esteem and depression from having to get help from people around them. For elderly stroke patients in the acute and subacute phases, during which neurological recovery often progresses rapidly, experiencing improvements in performance of ADLs, rather than satisfaction with the recognition of functional recovery, can be effective in providing a sense of security and controlling depression.

Meaningful activities that each individual should be able to perform daily include jobrelated specialized activities, hobbies, and sports-related activities. Enhancing performance of ADLs helps people progress towards achieving the goals of rehabilitation [11]. Kwon [12] stated that factors related to difficulties in performing ADLs include age, tetany, motivation, and changes in cognition and tetany of the upper limbs; in contrast, Wade et al. [13] and Jongbloed [14] stated that as age increases, treatment effectiveness decreases. The present study on elderly stroke patients illustrated significant improvements in performance of ADLs over time, and performance of ADLs was correlated with both functional status and depression. In relation to this, additional long-term follow-up monitoring on factors that influence the performance of ADLs in elderly stroke patients is needed. Furthermore, it would be beneficial for stroke patients if researchers found ways to increase the participation rate in rehabilitation through training and education on ADLs, and to increase the intrinsic motivation for achieving the goals of rehabilitation.

In the study by Song [15], Functional Independence Measure and Beck Depression Inventory scores had a significant influence on quality of life at all studied timepoints. This was consistent with the correlations between the GDS-K and K-MBI within 1 week, 1 month, and 3monthspost-stroke in the present study. Thus, for rehabilitation of elderly stroke patients, efforts should be made to ensure continual functional recovery, and training to improve ADLs should be provided stepwise from the initial stage of onset. Along with physical functional improvements, psychological problems in stroke patients such as depression and anxiety should be thoroughly examined and detected early, 
thereby allowing for control of these factors that negatively affect long-term rehabilitation.

\section{Conclusions}

The results indicate that both elderly stroke patients and healthy elderly experience primary physical and functional limitations due to neurological impairments, which makes them need to depend on others to perform everyday activities that were previously performed independently. Such limitations can, in turn, result in problems such as secondary psychological atrophy and loss of confidence, which can in turn affect patients' rehabilitation and bonds with their family and society, thus delaying their recovery. Therefore, to ensure that elderly stroke patients engage in maximum independent ADLs at the beginning of rehabilitation, various programs to enhance the intrinsic motivation and goal-setting, along with approaches to enhance functional status, need to be provided.

\section{References}

[1] J. H. Kim and T. R. Han, Rehabilitation Medicine, (2002).

[2] E. J. Chu, "A study on the cognitive function, depression and relationship of the elderly suffering from stroke", Master's Thesis, (2008).

[3] Y. A. Han, "Analysis of in daily activities, family support and depression in hemiparesis patients due to stroke", Master's Thesis, (2004).

[4] K. H. Park, "Association for daily activities with depression and anxiety in stroke patients", Master's Thesis, (2007).

[5] M. Aström, R. Adolfsson and K. Asplund, "Major depression in stroke patients: a 3-year longitudinal study”, Storke, vol. 24, no. 7, (1993), pp. 976-982.

[6] Y. C. Kwon and J. H. Park, "Standardization of korean version of the mini-mental state examination (MMSE-K) for use in the elderly, -Part I : korean version of mini-mental state examination(MMSE-K)", The Journal of Korean Neuropsychiatric association, vol. 28, no. 3, pp. 125-135.

[7] K. M. Lee, Y. H. Jang, Y. H. Kim, S. K. Moon, J. H. Park, S. W. Park, H. J. Yu, S. G. Lee, M. H. Chun and T. R. Han, "Reliability and validity of korean version of national institutes of health stroke scale, multi-center study", The Journal of Korean Academy of Rehabilitation Medicine, vol. 28, no. 5, (2004), pp. 422-433.

[8] H. Y. Jung, B. K. Park, H. S. Shin, Y. K. Kang, S. B. Pyun, N. J. Paik and T. R. Han, "Development of the Korean version of modified barthel index(K-MBI): multi-center study for subjects with stroke", The Journal of Korean Academy of Rehabilitation Medicine, vol. 31, no. 3, (2007), pp. 283-297.

[9] B. S. Kee, "A preliminary study for the standardization of geriatric depression scale short form-korea version", The Journal of Korean Neuropsychiatric association, vol. 131, no. 2, (1996), pp. 298-307.

[10] M. L. Hackett, C. Yapa, V. Parag and C. S. Anderson, "Frequency of depression after stroke: a systematic review of observational studies", Stroke, vol. 36, no. 6, (2005), pp. 1330-1340.

[11] C. A. Trombly and M. V. Randomski, "Occupational therapy for physical dysfunction", (2002).

[12] O. Y. Kwon, "Factors influencing rehabilitation outcome in hemiplegic patient", Master's Thesis (1992).

[13] M. F. Wade, C. E. Skillbeck and P. L. Hewer, "Predicting Barthel ADL score 6 months after an acute stroke", Arch Phys Med Rehabil, vol. 64, no. 1, (1983), pp. 24-28.

[14] L. Jongloed, "Prediction of function after stroke", Stroke, vol. 17, no. 4, (1986), pp. 765-776.

[15] I. J. Song, "Change the quality of life according to elapsing time in stroke patient", Doctoral dissertation, (2012).

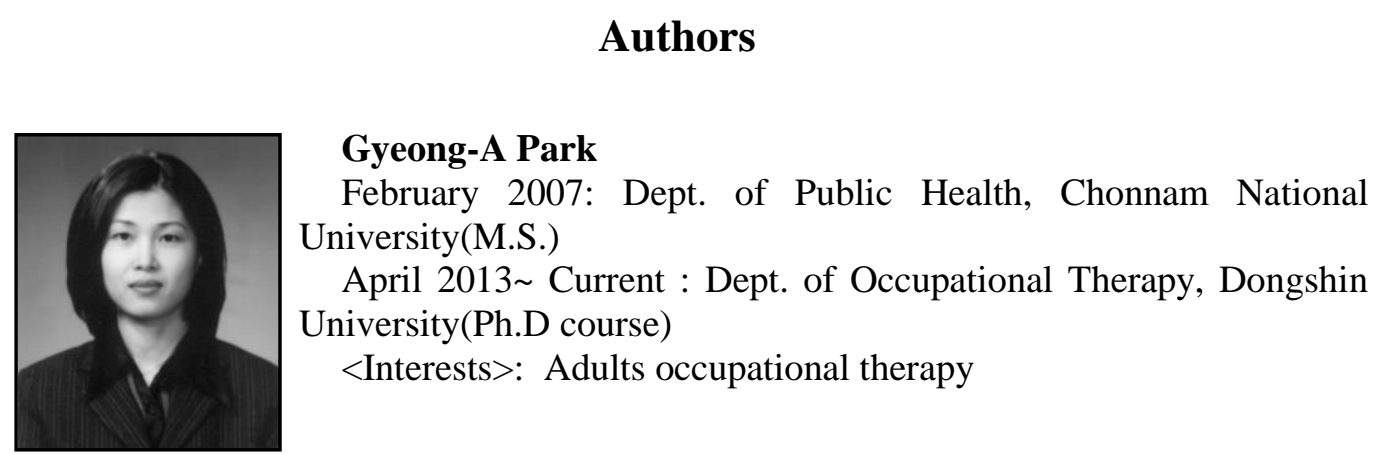




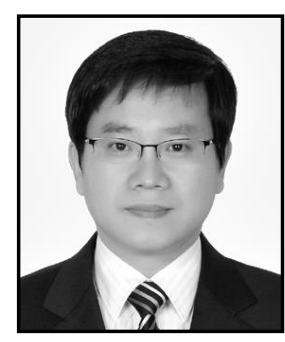

\section{Keun-Bae Oh}

February 2005: Dept. of Physical Therapy \& Occupational Therapy, Dankook University(M.S.)

September 2012 Current : Dept. of Physical Rehabilitation, Bucheon Sungshim Hospital

<Interests>: Neurological Physical therapy

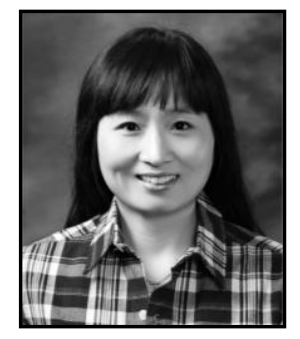

\section{Jin-A Hwang}

February 2013: Dept. of Physical Therapy, Dongshin University(M.S.)

April 2013 Current : Dept. of Physical Therapy, Dongshin University(Ph.D course)

<Interests>: Musculoskeletal Physical therapy

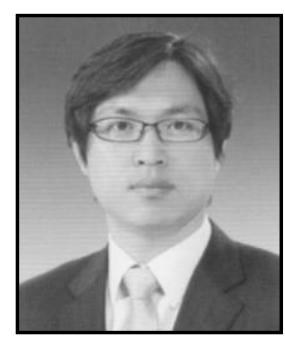

\section{Kyung-Yoon Kim}

February 2004: Dept. of Physical Therapy, Dongshin University(M.S.)

February 2007: Dept. of Physical Therpay, Dongshin University(Ph.D.)

March 2006 Current : Dept. of Phycial Therapy, Dongshin University(Professor)

<Interests>: Neuroscience, Neurological physical therapy

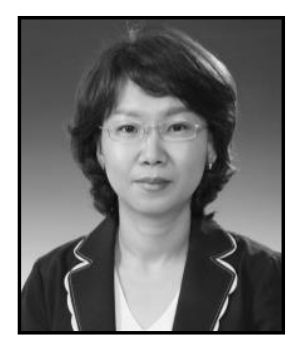

\section{Ji-Young Baik}

February 2001: Dept. of Physical Therapy \& Occupational Therapy, Dankook University(M.S.)

August 2008 : Dept. Physical Therapy \& Occupational Therapy, Dankook University(Ph.D.)

April 2009 Current : Dept. of Occupational Therapy, Dongshin University(Professor)

<Interests>: Neuroscience, Neurological occupational therapy 